\title{
Effect of temperature on the fluidity of boar sperm membranes*
}

\author{
A. T. Canvin and M. M. Buhr† \\ Department of Animal Science, University of Manitoba, Winnipeg, Manitoba, Canada R3T 2N2
}

\begin{abstract}
Summary. Fluidity was used to assess changes in molecular organization of boar spermatozoa plasma membranes from (1) the head and (2) the rest of the sperm body and acrosome as a consequence of temperature. The initial fluidity of the head membranes at $25^{\circ} \mathrm{C}$ was less than that of the sperm body membranes $(P<0.05)$. When held at $25^{\circ} \mathrm{C}$, the fluidity of the head membranes decreased for $105 \pm 8 \mathrm{~min}$ and then stabilized for the remainder of the 160 -min incubation. Calcium $(10 \mathrm{~mm})$ caused a significantly greater decrease in fluidity. The fluidity of the sperm body membranes increased slightly over time in the absence of $\mathrm{Ca}^{2+}$, but decreased significantly with $\mathrm{Ca}^{2+}$. Cooling from 25 to $5^{\circ} \mathrm{C}$ and subsequent heating to $40^{\circ} \mathrm{C}\left(0 \cdot 4^{\circ} \mathrm{C} / \mathrm{min}\right)$ caused marked alterations in the fluidity of each membrane. Cooling the head membranes prevented the fluidity increase seen at $25^{\circ} \mathrm{C}$, while reheating caused a dramatic decrease in fluidity. Fluidity of the head membranes was now unaffected by $\mathrm{Ca}^{2+}$. Lipid phase transitions, indicated by sharp break points in data curves, were detected at the onset of reheating $\left(7 \pm 3^{\circ} \mathrm{C}\right)$ and at $23 \pm 4^{\circ} \mathrm{C}$ during reheating. Fluidity of the sperm body membranes decreased slightly and in a linear fashion with $\mathrm{Ca}^{2+}$. Without $\mathrm{Ca}^{2+}$, the sperm body membranes showed an additional lipid phase shift at $31 \pm 5^{\circ} \mathrm{C}$, which led to a rapid fall in fluidity. These results suggest that the fluidity, and therefore the molecular structure, of sperm head and body membranes differ. The head plasma membranes, and to a lesser extent the sperm body membranes, undergo a fluidity change over time, which may reflect the structural reorganization of capacitation. This fluidity pattern is significantly disrupted by cooling and reheating.
\end{abstract}

Keywords: boar; spermatozoa; membranes; fluidity; temperature

\section{Introduction}

Communication between a cell and its environment is mediated by the plasma membrane. The fluid mosaic model predicts that such communication would be affected by the ability of the molecules within the membrane to interact with each other and with the cytoplasm and/or extracellular environment. Other mammalian tissues show a correlation of function with membrane structure. As luteal progesterone production drops, luteal membranes show an increase in gel phase lipid detected by X-ray diffraction (Buhr et al., 1979) and a decrease in fluidity detected by fluorescence polarization (Carlson et al., 1984).

Insemination with boar semen thawed after frozen storage reduces both the farrowing rate and the litter size (Johnson et al., 1981). The fertility of such semen is not correlated with sperm motility, and is only poorly correlated with acrosomal morphology (Wilmut \& Polge, 1977). Such loss of function may therefore be due to changes in the plasma membrane of the sperm head.

\footnotetext{
*Reprint requests to Dr M. M. Buhr.

$\dagger$ Present address: Department of Animal and Poultry Science, Ontario Agricultural College, University of Guelph, Guelph, Ontario, Canada N1G 2W1.
} 
Ram spermatozoa have been shown to undergo temperature-dependent changes in both membrane structure and in the activity of membrane-bound enzymes (Holt \& North, 1986). If temperature manipulations induce similar alterations in the plasma membrane surrounding the head of boar spermatozoa, some of the normal membrane-dependent events in capacitation and fertilization might be adversely affected. The head plasma membranes might undergo irreversible alterations in ultrastructure resulting from the cooling and reheating process. These alterations could be unique to the head plasma membrane, since this membrane is structurally different from those of the acrosome and the rest of the sperm body (Peterson \& Russell, 1985; de Curtis et al., 1986).

\section{Materials and Methods}

Sample preparation. Semen was collected by the gloved-hand technique from mature boars of known fertility. The whole ejaculate was strained through 2 layers of J-cloth into a vacuum flask maintained at $37^{\circ} \mathrm{C}$. Semen was evaluated for motility and morphology and normal semen ( $>65 \%$ motility, $<20 \%$ abnormal) was filtered twice at $25^{\circ} \mathrm{C}$ through Miracloth (Calbiochem, La Jolla, CA, USA) and diluted 1:1 (v/v) with Buffer l (5 mM Tris- $\mathrm{HCl}, 0.25 \mathrm{M}-$ sucrose, $\mathrm{pH} 7.4)$ at $25^{\circ} \mathrm{C}$. A $1: 1(\mathrm{v} / \mathrm{v})$ mixture of 550 and 1107 silicon oils (Dow Corning, Mississauga, Ontario, Canada) was centrifuged ( $1500 \mathrm{~g}, 10 \mathrm{~min})$, and the supernatant harvested. The buffered semen was layered on an equal volume of this supernatant and centrifuged $(2500 \mathrm{~g}, 10 \mathrm{~min})$ to remove seminal plasma and debris $(\mathrm{P}$. F. Watson, personal communication).

Subsequent membrane isolation was by a variation of the procedure of Gillis et al. (1978). Briefly, the sperm pellet was washed 3 times $(2500 \mathrm{~g}, 10 \mathrm{~min})$ and the final pellet brought up to $30 \mathrm{ml}$ in Buffer I. The pellet was subjected to nitrogen cavitation in a Parr bomb at $116 \mathrm{~kg} / \mathrm{cm}^{2} \mathrm{~N}_{2}$ for $10 \mathrm{~min}$, extruded into $30 \mathrm{ml}$ Buffer II ( $5 \mathrm{M}$ Tris- $\mathrm{HCl}, 0.25 \mathrm{M}$ sucrose, $\mathrm{pH} 5.0$ ) and shaken vigorously by hand for $1 \mathrm{~min}$ to separate membrane vesicles (Kaplan et al., 1984). The cavitate was washed three times in Buffer II $(1000 \mathrm{~g}, 10 \mathrm{~min})$; the pellet contained intact spermatozoa minus much of the head membranes (Peterson et al., 1980). This pellet was designated as sperm body membranes for fluorescence polarization. The combined supernatants were centrifuged $(6000 \mathrm{~g}, 10 \mathrm{~min})$ to remove remaining intact cells and the supernatant was centrifuged $(365000 \mathrm{~g}, 60 \mathrm{~min})$. The resultant pellet was resuspended in Buffer III $(10 \mathrm{mM} \mathrm{Tris}-\mathrm{HCl}$, $0.9 \%(\mathrm{w}: \mathrm{v}) \mathrm{NaCl}, \mathrm{pH} 7.4)$, centrifuged $(365000 \mathrm{~g}, 30 \mathrm{~min})$ and the pellet of head plasma membranes was transferred in $2 \mathrm{ml}$ Buffer II to a glass-Teflon homogenizer. After 10-15 strokes of the pestle, protein concentrations in the head and sperm body membranes were determined (Bradford, 1976) using bovine gamma globulin (Sigma, St Louis, MO, USA) as a standard. Membrane samples were diluted with Buffer III to a final concentration of $200 \mu \mathrm{g} / \mathrm{ml}$.

Membrane analyses. To determine fluidity, fluorescence measurements were taken on a model LS5 Perkin Elmer spectrofluorometer fitted with a polarizing accessory, using excitation and emission slit widths of $10 \mathrm{~nm}$ and $5 \mathrm{~nm}$, respectively. A stock solution ( $2 \mathrm{mM})$ of the probe molecule trans-parinaric acid (tPNA: Molecular Probes Inc., Junction City, OR, USA) was made fresh every 3 months and stored in the dark under $\mathrm{N}_{2}$ at $-20^{\circ} \mathrm{C}$. At $1 \mathrm{~h}$ before use, it was diluted to $4 \mu \mathrm{M}$ in Buffer III. Equal volumes $(1.5 \mathrm{ml})$ of tPNA and sample were mixed and allowed to equilibrate for $10 \mathrm{~min}$; final concentrations were $2 \mu \mathrm{M}-\mathrm{tPNA}$ and $100 \mu \mathrm{g}$ protein $/ \mathrm{ml}$. Calcium was added as $\mathrm{CaCl}_{2}$ to the appropriate samples with vigorous pipetting before the equilibration period; final concentration was $10 \mathrm{~mm}$. Excitation and emission wavelength maxima were determined daily and were very consistent $(324 \pm 0.6 \mathrm{~nm}$ (mean \pm s.e.) and $420 \pm 0.5 \mathrm{~nm}$, respectively). Sample temperature was controlled by a Lauda RC3 circulating water bath attached to the cuvette holder, and monitored directly with a thermocouple in a sample cuvette. Fluorescence was assessed continuously for $160 \mathrm{~min}$ at $25^{\circ} \mathrm{C}$ or while cooling from 25 to $5^{\circ} \mathrm{C}$ and heating to $40^{\circ} \mathrm{C}$ at an approximate rate of $0.4^{\circ} \mathrm{C}$ per min. Fluorescence intensities were transformed into polarization values using the Perrin equation (Shinitzky \& Barenholz, 1978):

$$
\mathbf{P V}=\frac{\mathbf{I}_{\|} / \mathbf{I}_{\perp}-1}{\mathrm{I}_{\|} / \mathbf{I}_{\perp}+1}
$$

with $I_{\|}$and $I_{\perp}$ representing the emission intensities from photomultiplier tubes polarized parallel and perpendicular, respectively, to the plane of the incident light (excitation beam).

The activity of alkaline phosphatase, a marker enzyme for sperm head plasma membrane (Noland et al., 1983), was assessed by the method of Linhardt \& Walter (1963), using $p$-nitrophenyl-phosphate (Sigma) as a substrate.

Statistical analysis. Initial polarization values were analysed for differences using least square means and their predicted differences. Polarization values were adjusted within trials by subtracting the value at time zero from all values to reduce variation due to differences in initial values. Data were analysed by stepwise regression on a polynomial equation with time and powers of time as the dependent variables. If data were non-linear $(P<0.05)$ then a procedure to fit a series of straight-line segments was invoked. The NLIN procedure (SAS Inc., 1985) fitted the series of line segments simultaneously, using the criteria of minimum residual sums of squares to estimate the various slopes and intercepts. This procedure also estimated the points on the $x$-axis at which the lines changed direction (break points). If data were linear, slopes were compared using a $t$ test for parallelism. 


\section{Results}

Alkaline phosphatase activity of the head plasma membrane preparation was $421 \pm 55 \%$ (mean \pm s.e.) compared to $100 \%$ for intact spermatozoa and $93 \pm 10 \%$ for sperm body membranes.

The initial absolute, unadjusted polarization value indicated that the head plasma membrane was less fluid than the sperm body membrane. Calcium had no effect (Table 1). Fluidity changed over time at $25^{\circ} \mathrm{C}$ in a manner unique to each membrane type (Fig. 1). Fluidity of the head plasma membranes decreased over time, with $\mathrm{Ca}^{2+}$ significantly speeding the rate at which the overall fluidity declined (slope, Table 2). Break points were apparent in head plasma membrane slopes and were also affected by $\mathrm{Ca}^{2+}$ (Table 3 ). The polarization value of the sperm body membrane (Fig. 1) in the absence of $\mathrm{Ca}^{2+}$ described a bipartite line with an initially flat slope which subsequently decreased, indicative of increased fluidity. This differed significantly from the linear decrease in fluidity of the sperm body membrane in the presence of $\mathrm{Ca}^{2+}$. Temperature significantly affected the fluidity characteristics of both the head and the sperm body membranes (Fig. 2). Cooling the head plasma membranes maintained the initial fluidity, while with onset of heating there was an immediate, rapid decrease in fluidity. The overall slopes and break points (Table 4) for the head plasma membranes were similar in the presence or absence of $\mathrm{Ca}^{2+}$, although $\mathrm{Ca}^{2+}$ tended to increase fluidity. Fluidity of the sperm body membranes decreased gradually through cooling and reheating, with a rapid decrease in fluidity starting at $31 \pm 5^{\circ} \mathrm{C}$ in the absence of $\mathrm{Ca}^{2+}$ (Table 3).

Table 1. Initial polarization values (least square means) of boar sperm membranes

\begin{tabular}{lcccc}
\hline & \multicolumn{2}{c}{$\left[\mathrm{Ca}^{2+}\right]$} & & \\
\cline { 2 - 3 } Membrane & 0 & $10 \mathrm{mM}$ & s.e.m. & $n$ \\
\hline Head & $0.4259^{\mathrm{a}}$ & $0.4330^{\mathrm{a}}$ & 0.01065 & 18 \\
Sperm body & $0.3697^{\mathrm{b}}$ & $0.3792^{\mathrm{b}}$ & 0.01065 & 18 \\
\hline
\end{tabular}

${ }^{\mathrm{a}, \mathrm{b}}$ Means with different superscript letters differ $(P<0.05)$.

Table 2. Characteristics of fluidity curves of boar sperm membranes at $25^{\circ} \mathrm{C}$

\begin{tabular}{|c|c|c|c|}
\hline Membranes & $\begin{array}{l}\text { Start } \\
(\mathrm{min})\end{array}$ & $\begin{array}{c}\text { Slope } \\
\text { (polarization value } \\
\left./ \min \times 10^{-4}\right)\end{array}$ & $n$ \\
\hline Sperm body & & & 4 \\
\hline Slope 1 & 0 & $-0.5 \pm 0.7$ & \\
\hline Slope 2 & $88 \pm 30$ & $-2 \cdot 6 \pm 1 \cdot 1$ & \\
\hline Sperm body $+\mathrm{Ca}^{2+}$ & & & 4 \\
\hline $\begin{array}{l}\text { Total slope } \\
\text { (linear) }\end{array}$ & 0 & $5 \cdot 6 \pm 0 \cdot 5$ & \\
\hline Head & & & 4 \\
\hline Slope 1 & 0 & $5 \cdot 3 \pm 0$ & \\
\hline Slope 2 & $105 \pm 8$ & $0 \pm 1 \cdot 3$ & \\
\hline Head $+\mathrm{Ca}^{2+}$ & & & 4 \\
\hline Slope 1 & 0 & $19 \cdot 2 \pm 5 \cdot 5$ & \\
\hline Slope 2 & $44 \pm 10$ & $3.9 \pm 1.0$ & \\
\hline
\end{tabular}

Values are mean \pm s.e. 
Table 3. Break points in fluidity curves of boar sperm membranes

\begin{tabular}{|c|c|c|c|}
\hline \multirow[b]{3}{*}{ Membranes } & \multicolumn{3}{|c|}{ Break points } \\
\hline & \multicolumn{2}{|c|}{$\begin{array}{c}\text { At variable } \\
\text { temperature } \\
(n=5)\end{array}$} & \multirow{2}{*}{$\begin{array}{c}\text { At constant } \\
\text { temperature } \\
(n=4)\end{array}$} \\
\hline & Minutes & Equivalent ${ }^{\circ} \mathrm{C}$ & \\
\hline Sperm body & $\begin{array}{r}25 \pm 16 \\
133 \pm 5\end{array}$ & $\begin{array}{l}16 \text { (d) } \pm 5 \\
31 \text { (i) } \pm 5\end{array}$ & $88 \pm 30$ \\
\hline Sperm body $+\mathrm{Ca}^{2+}$ & ND & - & ND \\
\hline Head plasma & $\begin{array}{r}64 \pm 10 \\
111 \pm 11\end{array}$ & $\begin{array}{r}7 \text { (i) } \pm 3 \\
23 \text { (i) } \pm 4\end{array}$ & $105 \pm 8$ \\
\hline Head plasma $+\mathrm{Ca}^{2+}$ & $\begin{array}{r}62 \pm 4 \\
137 \pm 6\end{array}$ & $\begin{array}{r}6 \text { (i) } \pm 1 \\
32 \text { (i) } \pm 2\end{array}$ & $44 \pm 10$ \\
\hline
\end{tabular}

ND = non-detectable; (d) = decreasing temperature; (i) = increasing temperature.

Values are mean \pm s.e.

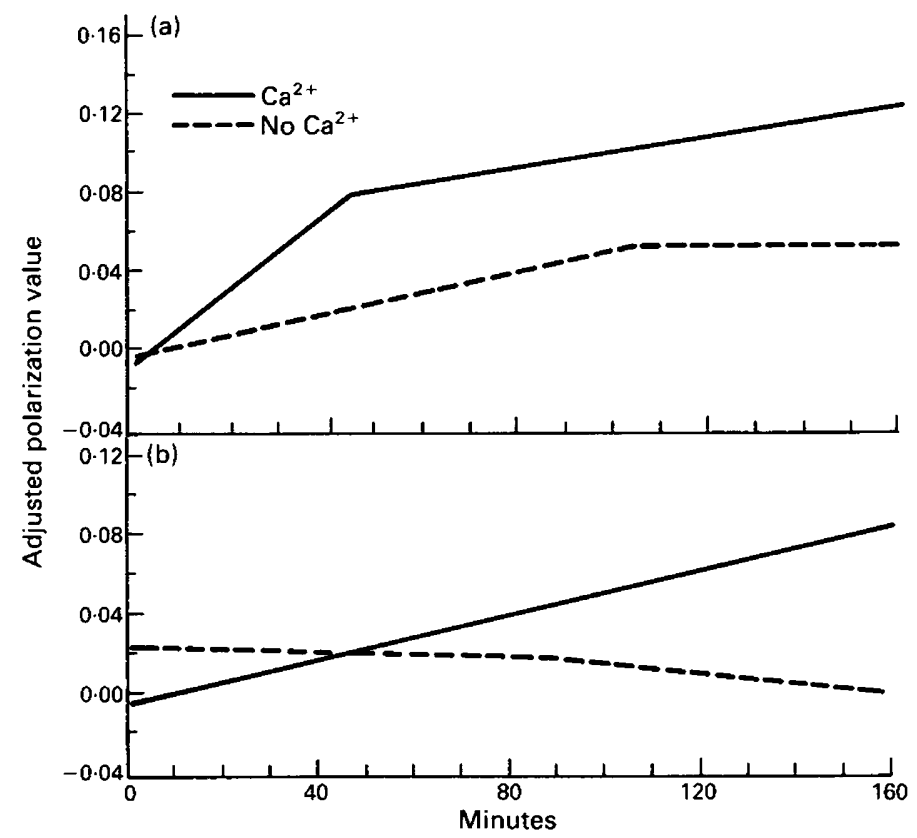

Fig. 1. Changes in fluidity of boar sperm head plasma membrane (a) and the sperm body membrane (b) fraction at $25^{\circ} \mathrm{C}$ in the presence or absence of $10 \mathrm{~mm}-\mathrm{Ca}^{2+}$. Each line was generated from data in 4 replicate trials. Increasing polarization value indicates decreasing fuidity. 


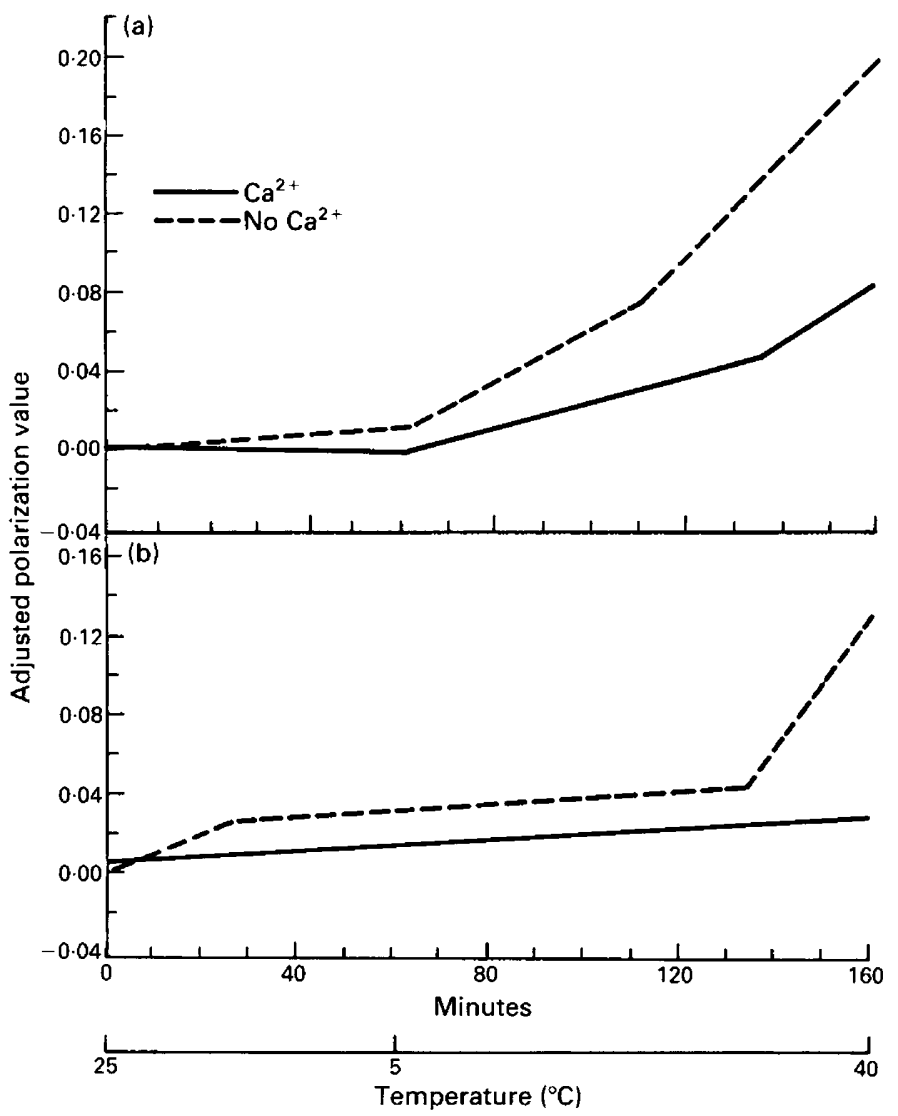

Fig. 2. Changes in fluidity of boar sperm head plasma membrane (a) and sperm body membrane (b) during cooling $\left(25-5^{\circ} \mathrm{C}\right)$ and subsequent reheating $\left(5-40^{\circ} \mathrm{C}\right)$, in the presence or absence of $10 \mathrm{mM}-\mathrm{Ca}^{2+}$. Increasing polarization value indicates decreasing fluidity. Each line was generated from data in 5 replicate trials.

Table 4. Characteristics of fluidity curves of boar sperm membranes at variable temperatures

\begin{tabular}{|c|c|c|c|c|}
\hline Membranes & $\begin{array}{l}\text { Start } \\
(\mathrm{min})\end{array}$ & $\begin{array}{c}\text { Equivalent } \\
{ }^{\circ} \mathrm{C}\end{array}$ & $\begin{array}{c}\text { Slope } \\
\text { (polarization value } \\
/ \mathrm{min} \times 10^{-4} \text { ) }\end{array}$ & $n$ \\
\hline Sperm body & & & & 5 \\
\hline Slope 1 & 0 & 25 (d) $\pm 0^{*}$ & $10 \cdot 2 \pm 6 \cdot 6$ & \\
\hline Slope 2 & $25 \pm 16$ & $16(d) \pm 5$ & $1 \cdot 6 \pm 1 \cdot 1$ & \\
\hline Slope 3 & $133 \pm 5$ & 31 (i) \pm 5 & $34.8 \pm 8.6$ & \\
\hline Sperm body $+\mathrm{Ca}^{2+}$ & 0 & 25 (d) $\pm 0^{*}$ & $1.5 \pm 0.3$ & 5 \\
\hline Head plasma & & & & 5 \\
\hline Slope 1 & 0 & $25(\mathrm{~d})^{*}$ & $1 \cdot 7 \pm 1 \cdot 7$ & \\
\hline Slope 2 & $64 \pm 10$ & 7 (i) \pm 3 & $13 \cdot 2 \pm 3 \cdot 3$ & \\
\hline Slope 3 & $111 \pm 11$ & 23 (i) \pm 4 & $25 \cdot 5 \pm 3 \cdot 3$ & \\
\hline Head plasma $+\mathrm{Ca}^{2+}$ & & & & 5 \\
\hline Slope 1 & 0 & $25(\mathrm{~d}) \pm 0^{*}$ & $-0.7 \pm 0.8$ & \\
\hline Slope 2 & $62 \pm 4$ & 6 (i) \pm 1 & $6.4 \pm 0.6$ & \\
\hline Slope 3 & $137 \pm 6$ & 32 (i) \pm 2 & $15 \cdot 7 \pm 3 \cdot 2$ & \\
\hline
\end{tabular}

(d) = decreasing temperature; (i) $=$ increasing temperature.

*Start temperature.

Values are mean \pm s.e. 


\section{Discussion}

The two membrane fractions described here as the head plasma membrane and sperm body membranes differ dramatically. The activity of the head plasma membrane marker enzyme alkaline phosphatase (Noland et al., 1983) was considerably enriched in the head membrane fraction. The known structural differences between the head and sperm body membranes (Vijayasarathy \& Balaram, 1982) also were evident in fluidity measurements. Fluorescence polarization is a sensitive test of the fluidity of the membrane lipid bilayer, which reflects the molecular organization of the membrane in the vicinity of the probe molecule (Shinitzky \& Barenholz, 1978). These pig sperm head membranes initially were less fluid than the body membranes, in contrast to bull sperm plasma membranes, which are more fluid than acrosomal membranes (Vijayasarathy et al., 1982). In both species, however, the fluidity and therefore molecular structure of the head membranes differ from those of the membranes of the rest of the spermatozoon. The differences in absolute values could result from the varied components in the sperm body membranes, procedural differences in membrane preparation or species differences.

The sperm body membranes also differed from head membranes in fluidity patterns at $25^{\circ} \mathrm{C}$. Motility of fowl spermatozoa (Ashizawa \& Wishart, 1987) and activity of ATPase in flagellar membranes of bovine spermatozoa (Vijayasarathy \& Balaram, 1982) require $\mathrm{Ca}^{2+}$ and $\mathrm{Ca}^{2+}$ also is bound specifically to acrosomal membranes of ejaculated boar spermatozoa (Berruti \& Franchi, 1986). Calcium in the current study caused a steady decrease in fluidity, perhaps due to these functions of the varied components of this fraction. Temperature-dependent $\mathrm{Ca}^{2+}$ sensitivity also differs between the sperm head and body membranes, both in the nature of the temperatureinduced fluidity change and in the retention of $\mathrm{Ca}^{2+}$ sensitivity by the body membranes in all circumstances. The sperm head and body membranes therefore differ in enzyme activity and fluidity characteristics in the presence or absence of $\mathrm{Ca}^{2+}$.

Capacitation and the acrosome reaction involve extensive changes in the organization of head plasma membrane domains and vesiculation of the membranes. Plasma membrane proteins are re-organized during sperm maturation and ejaculation (Saxena et al., 1986) and during ejaculation (Ahuja, 1984) and lipid diffusibility changes during hyperactivation (Wolf et al., 1986). The fluidity of the head membranes decreased with time at $25^{\circ} \mathrm{C}$, either reflecting or actually monitoring the membrane dynamics of the final achievement of fertilizing ability. Calcium caused a further, bipartite decrease in fluidity, perhaps indicative of a biphasic effect of a relatively high $\mathrm{Ca}^{2+}$ concentration on sperm fertilizing ability. Fraser (1987) noted that exposure of mouse spermatozoa to $3.6 \mathrm{~mm}-\mathrm{Ca}^{2+}$ accelerated capacitation; increased exposure decreased fertilizing ability with no further effect on acrosomes or motility.

Cooling and reheating the head plasma membrane of boar spermatozoa significiantly shifted these fluidity patterns. Logically, cooling should decrease lipid fluidity and heating increase it. Holt \& North (1986), using the probe diphenylhexatriene (DPH), found that higher temperatures did increase the fluidity of mixed head and tail membranes from ram spermatozoa. In the current study, cooling head membranes from boar spermatozoa prevented the normal decrease in fluidity and heating decreased fluidity at a higher rate and in a different pattern. The tPNA probe molecule preferentially inserts into gel phase lipids (Sklar et al., 1979a). It monitors the most ordered areas of the membrane and can detect phase variations undetectable by DPH (Carlson et al., 1984). Lipids shifting to the gel phase would be preferentially monitored by tPNA, which suggests that these temperature-induced fluidity changes could either be occurring in specific domains within the membrane or throughout the membrane.

Cooling and reheating also affected the onset of lipid phase shifts in the boar sperm head membrane, indicated by the different break points in the constant and variable temperature regimens (Sklar et al., 1979b). Holt \& North (1986) detected thermotropic phase shifts in mixed membranes from ram spermatozoa. Their phase shifts appeared to be of considerably lower magnitude than those described here. This may be due to the different membrane fraction, different 
species, different probe, or temperature variations which occurred during the storage and analysis of the ram membranes. The current study isolated all boar membranes at $25^{\circ} \mathrm{C}$, analysed them on the day of isolation and controlled the rate of temperature change $\left(0 \cdot 4^{\circ} \mathrm{C} / \mathrm{min}\right)$ during the fluorescence analysis. The resultant data clearly demonstrate a differential temperature sensitivity between head and body membranes from boar spermatozoa.

This study has demonstrated that the fluidity, and therefore the molecular organization, of plasma membranes from the head and body of boar spermatozoa differ. The head plasma membrane is particularly dynamic, and its structure naturally changes over time at a constant temperature. Cooling and reheating significantly alter membrane molecular organization and may thereby alter membrane and sperm function.

This research was generously supported by the Manitoba Hog Producers' Marketing Board and Agriculture Canada.

\section{References}

Ahuja, K.K. (1984) Lectin-coated agarose beads in the investigation of sperm capacitation in the hamster. Devl Biol. 104, 131-142.

Ashizawa, K. \& Wishart, G.J. (1987) Resolution of the sperm motility-stimulating principle of fowl seminal plasma into $\mathrm{Ca}^{2+}$ and an unidentified low molecular weight factor. J. Reprod. Fert. 81, 495-499.

Berruti, G. \& Franchi, E. (1986) Calcium and polyphosphoinositides: their distribution in relation to the membrane changes occurring in the head of boar spermatozoa. Eur. J. Cell Biol. 41, 238-245.

Bradford, M.M. (1976) A rapid and sensitive method for the quantitation of microgram quantities of protein utilizing the principle of protein-dye binding. Analyt. Biochem. 72, $248-254$.

Buhr, M.M., Carlson, J.C. \& Thompson, J.E. (1979) A new perspective on the mechanism of corpus luteum regression. Endocrinology 105, 1330-1335.

Carlson, J.C., Buhr, M.M. \& Riley, J.C. (1984) Alterations in the cellular membranes of regressing rat corpora lutea. Endocrinology 114, 521-526.

de Curtis, I., Fumagalli, G. \& Borgese, N. (1986) Purification and characterization of two plasma membrane domains from ejaculated bull spermatozoa. J. Cell Biol. 102, 1813-1825.

Fraser, L.R. (1987) Minimum extracellular $\mathrm{Ca}^{2+}$ requirements during mouse sperm capacitation and fertilization in vitro. J. Reprod. Fert. 81, 77-89.

Gillis, G., Peterson, R., Russell, L., Hook, L. \& Freund, M. (1978) Isolation and characterization of membrane vesicles from human and boar spermatozoa: Methods using nitrogen cavitation and ionophore induced vesiculation. Prep. Biochem. 8, 363-378.

Holt, W.V. \& North, R.D. (1986) Thermotropic phase transitions in the plasma membrane of ram spermatozoa. J. Reprod. Fert. 78, 447-457.

Johnson, L.A., Aalbers, J.G., Willems, C.M.T. \& Sybesma, W. (1981) Use of boar spermatozoa for artificial insemination. Fertilizing capacity of fresh and frozen spermatozoa in sows on 36 farms. $J$. Anim. Sci. 52, 1130-1136.

Kaplan, M., Russell, J.D., Peterson, R.N. \& Martan, J. (1984) Boar sperm cytoplasmic droplets: their ultrastructure, their numbers in the epididymis and at ejaculation and their removal during isolation of sperm plasma membranes. Tiss. Cell 16, 455-468.

Linhardt, H. \& Walter, K. (1963) Phosphatases. In Methods of Enzymatic Analysis, pp 779-787. Ed. H. U. Bergmeyer. Academic Press, New York.

Noland, T.D., Olson, G.E. \& Garbers, D.L. (1983) Purification and partial characterization of plasma membranes from bovine spermatozoa. Biol. Reprod. 29, 987-998

Peterson, R.N. \& Russell, L.D. (1985) The mammalian spermatozoon: A model for the study of regional specificity in plasma membrane organization and function. Tiss. Cell Res. 17, 769-791.

Peterson, R., Russell, L., Bundman, D. \& Freund, M. (1980) Evaluation of the purity of boar sperm plasma membranes prepared by nitrogen cavitation. Biol. Reprod. 23, 637-645.

SAS Institute Inc. (1985) SAS Users Guide: Statistics, Version 6 Edition, Cary, N.C.

Saxena, N.K., Russell, L.D., Saxena, N. \& Peterson, R.N. (1986) Immunofluorescence antigen localization on boar sperm plasma membranes: monoclonal antibodies reveal apparent new domains and apparent redistribution of surface antigens during sperm maturation and at ejaculation. Anat. Rec. 214, 238-252.

Shinitzky, M. \& Barenholz, Y. (1978) Fluidity parameters of lipid regions determined by fluorescence polarisation. Biochim. Biophys. Acta 515, 367-394.

Sklar, L.A., Miljanich, G.P., Bursten, S.L. \& Dratz, E.A. (1979a) Thermal lateral phase separations in bovine retinal rod outer segment membranes and phospholipids as evidenced by parinaric acid fluorescence polarisation and energy transfer. J. biol. Chem. 254, 9583-9591.

Sklar, L.A., Miljanich, G.P. \& Dratz, E.A. (1979b) Phospholipid lateral phase separation and the partition of cis-parinaric acid and trans-parinaric acid among aqueous, solid lipid, and fluid lipid phases. Biochemistry, N.Y. 18, 1707-1716.

Vijayasarathy, S. \& Balaram, P. (1982) Regional differentiation in bull sperm plasma membranes. Biochem. Biophys. Res. Commun. 108, 760-769.

Vijayasarathy, S., Shivaji, S. \& Balaram, P. (1982) Bull sperm plasma and acrosomal membranes: 
fluorescence studies of lipid phase fluidity. Biochem. Biophys. Res. Commun. 108, 585-591.

Wilmut, I. \& Polge, C. (1977) The low temperature preservation of boar spermatozoa. 3. The fertilizing capacity of frozen and thawed boar semen. Cryobiology 14, 483-491.
Wolf, D.E., Hagopian, S.S. \& Ishijima, S. (1986) Changes in sperm plasma membrane lipid diffusibility after hyperactivation during in vitro capacitation in the mouse. J. Cell Biol. 102, 1372-1377.

Received 28 June 1988 